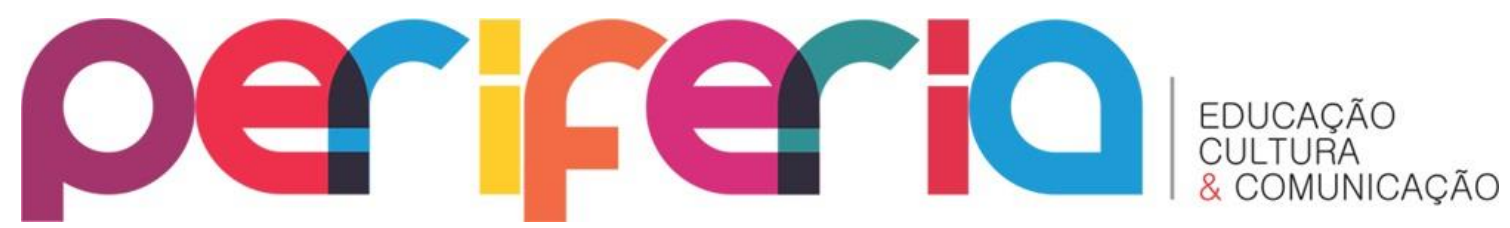

\title{
EM DEFESA DA EDUCAÇÃO DO CAMPO: enfrentando o desmonte das políticas públicas
}

\author{
Ramofly Bicalho ${ }^{1}$ \\ Pedro Clei Sanches Macedo ${ }^{2}$ \\ Guilherme Goretti Rodrigues ${ }^{3}$
}

\section{Resumo}

A educação do campo, enquanto direito histórico dos camponeses, possibilita as condições de superação da realidade de injustiças que marcam o campo brasileiro. Representa o acúmulo de experiências políticas dos movimentos sociais populares, por uma educação que respeite a diversidade dos sujeitos, individuais e coletivos, do campo, assim como, as condições materiais e subjetivas de vida, por meio da luta por reforma agrária popular. Por outro lado, a educação do campo, enquanto política pública, foi duramente atacada nos últimos anos, reflexo do avanço do discurso ultraconservador que ameaça o conjunto dos povos tradicionais que lutam, trabalham e produzem conhecimento no campo. Nesse sentido, este artigo tem por objetivo principal resgatar os elementos que sustentam as políticas públicas de educação do campo, fazendo frente ao atual cenário de retrocessos, por meio do fortalecimento dos movimentos sociais, educadores/as do campo, escolas e projetos político-pedagógicos emancipadores. Trata-se de uma apresentação de abordagem qualitativa, bibliográfica e documental, com reflexões que contemplem os desafios e estratégias de luta na atualidade, para manutenção das políticas públicas de educação do campo, historicamente conquistadas. 0 artigo documental foi desenvolvido em acervos bibliográficos. Entre as fontes de investigação, utilizamos legislações, portarias e decretos acerca das interfaces entre políticas públicas de

\footnotetext{
${ }^{1}$ Docente na UFRRJ - Universidade Federal Rural do Rio de Janeiro, Campus Seropédica. Lotado no Departamento de Educação do Campo, Movimentos Sociais e Diversidade. Docente na Licenciatura em Educação do Campo, no PPGEA - Programa de Pós-Graduação em Educação Agrícola e no PPGEduc Programa de Pós-Graduação em Educação, Contextos Contemporâneos e Demandas Populares. PósDoutorando em Educação na Universidade Federal Fluminense - UFF. Instituição: UFRRJ - Universidade Federal Rural do Rio de Janeiro. ORCID iD: http://orcid.org/0000-0003-0571-6481. E-mail: ramofly@gmail.com

2 Doutorando em Educação no Programa de Programa de Educação, Contextos Contemporâneos e Demandas Populares da UFRRJ; Mestre em Ciências no Programa de Pós-graduação em Educação Agrícola (PPGEA) da UFRRJ; membro do grupo de Pesquisa Educação do Campo, Movimentos Sociais e Pedagogia da Alternância da UFRRJ. Instituição: Instituto Federal do Amapá. ORCID iD: https://orcid.org/0000-0002-4873-7242. E-mail: pedroclei@hotmail.com.

${ }^{3}$ Doutorando em Educação no Programa de Programa de Educação, Contextos Contemporâneos e Demandas Populares da UFRRJ; membro do grupo de Pesquisa Educação do Campo, Movimentos Sociais e Pedagogia da Alternância da UFRRJ. Instituição: UFRRJ - Universidade Federal Rural do Rio de Janeiro. ORCID iD: https://orcid.org/0000-0002-4873-7242. E-mail:
} guilhermegoretti.geografia@gmail.com 


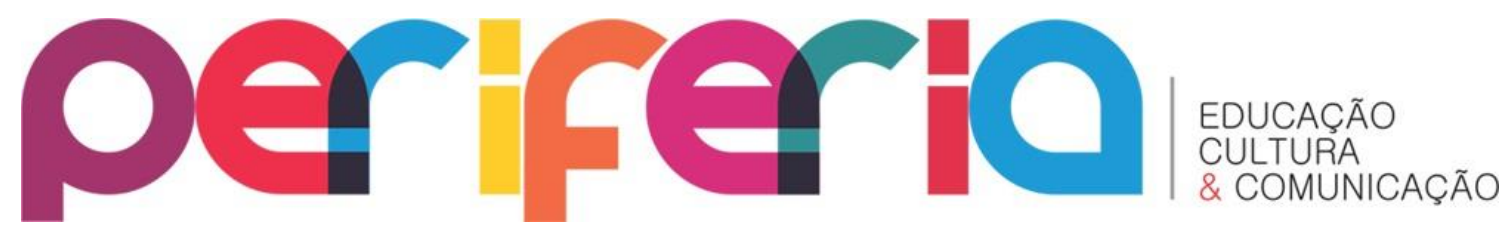

ISSN:1984-9540

DOI: $10.12957 /$ periferia.2021.55211

educação do campo e movimentos sociais. Concluímos que a educação do campo, como práxis libertadora, é utilizada no processo de compreensão das lutas e demandas educacionais defendida pelos movimentos sociais. Ela dialoga com os gestos, desejos, valores e a luta pela terra.

Palavras-chave: Movimentos Sociais; Educação do Campo; Políticas Públicas.

\section{IN DEFENSE OF FIELD EDUCATION: facing the dismantling of public policies}

\section{Abstract}

Rural education, as a historical right of peasants, allows the conditions to overcome the reality of injustices that mark the Brazilian countryside. It represents the accumulation of political experiences of popular social movements, for an education that respects the diversity of individuals, both individual and collective, in the countryside, as well as the material and subjective conditions of life, through the struggle for popular agrarian reform. On the other hand, rural education, as a public policy, has been severely attacked in recent years, reflecting the advancement of ultraconservative discourse that threatens the group of traditional peoples who struggle, work and produce knowledge in the field. In this sense, this article has as main objective to rescue the elements that support public policies of rural education, facing the current scenario of setbacks, through the strengthening of social movements, rural educators, schools and political-pedagogical projects. emancipators. It is a presentation of a qualitative, bibliographic and documentary approach, with reflections that contemplate the challenges and strategies of struggle today, to maintain the public policies of education in the countryside, historically achieved. The documentary article was developed in bibliographic collections. Among the sources of investigation, we use legislation, ordinances and decrees about the interfaces between public policies on rural education and social movements. We conclude that rural education, as liberating praxis, is used in the process of understanding the struggles and educational demands defended by social movements. It dialogues with gestures, desires, values and the struggle for land.

Keywords: Social Movements; Rural Education; Public policy.

\section{EN DEFENSA DE LA EDUCACIÓN DE CAMPO: enfrentando el desmantelamiento de las políticas públicas}

\section{Resumen}

La educación rural, como derecho histórico de los campesinos, permite las condiciones para superar la realidad de las injusticias que marcan el campo brasileño. Representa la acumulación de experiencias políticas de los movimientos sociales populares, por una educación que respete la diversidad de los individuos, tanto individuales como colectivos, en el campo, así como las condiciones materiales 


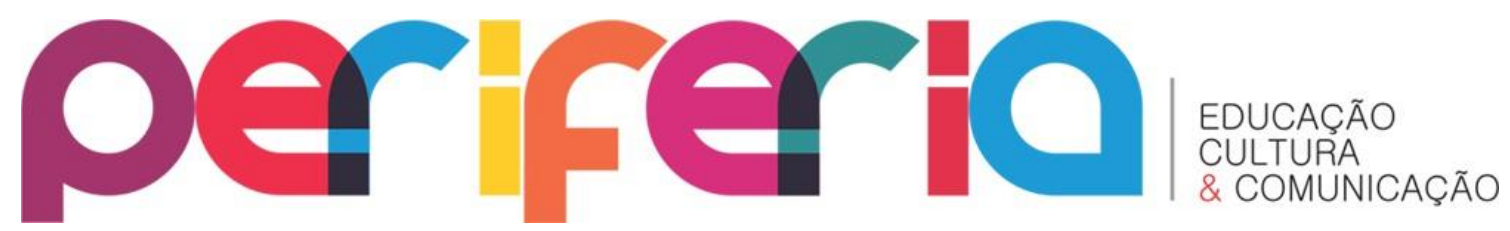

ISSN:1984-9540

DOI: $10.12957 /$ periferia.2021.55211

y subjetivas de vida, a través de la lucha por la reforma agraria popular. Por otro lado, la educación rural, como política pública, ha sido severamente atacada en los últimos años, reflejando el avance del discurso ultraconservador que amenaza al grupo de pueblos tradicionales que luchan, trabajan y producen conocimiento en el campo. En este sentido, este artículo tiene como principal objetivo rescatar los elementos que sustentan las políticas públicas de educación rural, ante el actual escenario de retrocesos, a través del fortalecimiento de los movimientos sociales, educadores rurales, escuelas y proyectos político-pedagógicos. emancipadores. Se trata de una presentación de un enfoque cualitativo, bibliográfico y documental, con reflexiones que contemplan los desafíos y estrategias de lucha hoy, para mantener las políticas públicas de educación en el campo, históricamente logradas. El artículo documental se desarrolló en colecciones bibliográficas. Entre las fuentes de investigación, utilizamos legislación, ordenanzas y decretos sobre las interfaces entre las políticas públicas de educación rural y los movimientos sociales. Concluimos que la educación rural, como praxis liberadora, se utiliza en el proceso de comprensión de las luchas y demandas educativas defendidas por los movimientos sociales. Dialoga con gestos, deseos, valores y la lucha por la tierra.

Palabras clave: Movimientos sociales. Educación rural. Políticas públicas.

\section{Introdução}

A consolidação da Educação do Campo percorre todo um processo histórico de intensas lutas, organização, disputas e manifestações na sociedade civil e no Estado, assim como é reflexo de muitos acúmulos políticos, intelectuais, filosóficos, de práticas, saberes dos movimentos sociais populares ${ }^{4}$ e dos sujeitos, individuais e coletivos, que vivem em múltiplas realidades e contextos no campo.

É importante sinalizar que esta consolidação se faz no interior de questões agrárias permeadas de contradições, avanços e retrocessos da luta camponesa, quilombola e indígena face à expansão do agronegócio, da mineração e dos projetos hegemônicos no campo, em detrimento das distintas formas de agricultura camponesa. Paralelo a esse processo de resistência, destacamos a luta dos movimentos sociais

\footnotetext{
${ }^{4}$ Para demarcar um campo conceitual, consideramos os movimentos sociais populares como aqueles que nascem das lutas populares, de sujeitos concretos oprimidos e subalternizados pelas relações de poder hegemônicas e capitalistas. De acordo com Ribeiro (2013, p.29) "são, portanto, os movimentos sociais populares os portadores do novo, do projeto popular de sociedade e de educação". 0 Movimento dos Trabalhadores Rurais Sem Terra (MST), o Movimento dos Atingidos por Barragens (MAB), a Coordenação Nacional de Articulação das Comunidades Negras Rurais Quilombolas (CONAQ), dentre outros, são exemplos de movimentos sociais populares a quem tomamos referência nesse artigo.
} 


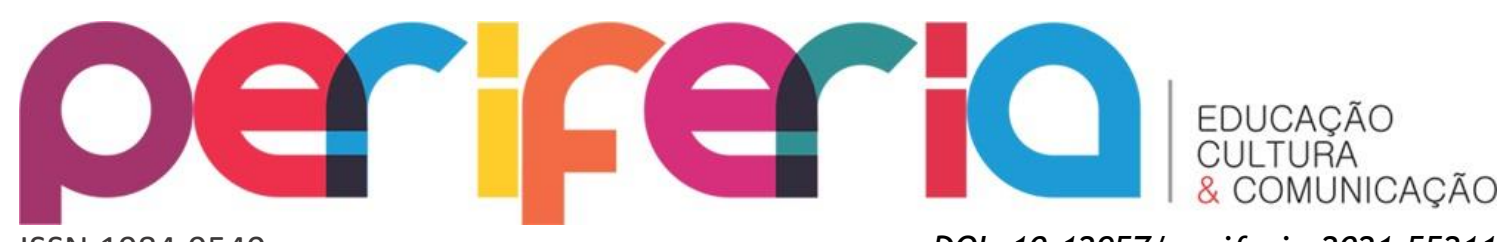

ISSN:1984-9540

DOI: $10.12957 /$ periferia.2021.55211

populares por direitos negados historicamente, enquanto consequência de decisões políticas e econômicas, tomadas pelos proprietários de terra e que se materializou espacialmente ao longo da formação territorial brasileira.

No campo educacional, evidenciamos ao longo da história como as políticas públicas foram negadas aos sujeitos que vivem no campo, reproduzindo preconceitos e estereótipos, tais como: sujeitos atrasados, sem história, sem cultura e memória. Entretanto, as organizações da sociedade civil, especialmente os movimentos camponeses, assim como quilombolas e indígenas, incluíram a educação do campo na pauta dos temas estratégicos para redemocratização do país. Com a Constituição Federal de 1988, a educação torna-se um direito público com a intenção de atender todos os indivíduos, independentemente se residem no campo ou na cidade.

No entanto, esse direito continua sendo negado. Constatamos nos últimos dez anos a intensificação do fechamento aleatório das escolas do campo no Brasil ${ }^{5}$. Diante deste cenário, é importante demonstrar a necessidade de fortalecimento das políticas públicas educacionais para os povos campesinos, com educadores e educadoras que compreendam a realidade das famílias camponesas a partir do respeito às histórias de vida, memórias e identidades dos sujeitos do campo. Do mesmo modo, a importância que os movimentos sociais populares, construídos por homens e mulheres, trabalhadores/as, assumem na atual realidade de tantos retrocessos e desmonte da educação e políticas públicas.

Para tanto, objetivamos neste trabalho resgatar os princípios da política de educação do campo, evidenciando os fundamentos que a sustentam para o fortalecimento das escolas do campo, seus educadores/as, assim como dos respectivos projetos político-pedagógicos. Torna-se relevante demarcar tais fundamentos, especialmente para reafirmar sua contribuição - resultado de construções coletivas -

\footnotetext{
${ }^{5}$ Segundo dados do Instituto Nacional de Colonização Reforma Agrária (INCRA), Programa Nacional de Educação na Reforma Agrária (PRONERA), Organização das Nações Unidas para a Educação, a Ciência e a Cultura (UNESCO), Universidade Estadual Paulista (UNESP), Instituto de Pesquisa Econômica Aplicada (IPEA) e II Pesquisa Nacional sobre Educação na Reforma Agrária (PNERA), a partir do relatório da II Pesquisa nacional sobre educação na Reforma Agrária, cerca de 32.512 escolas foram fechadas na última década. A Secretaria de Assuntos Estratégicos e o Ministério do Desenvolvimento Agrário (MDA) em 2015 informam que as escolas do campo foram reduzidas em 31,46\% (GUIMARÃES; BICALHO, 2017, p. 146).
} 


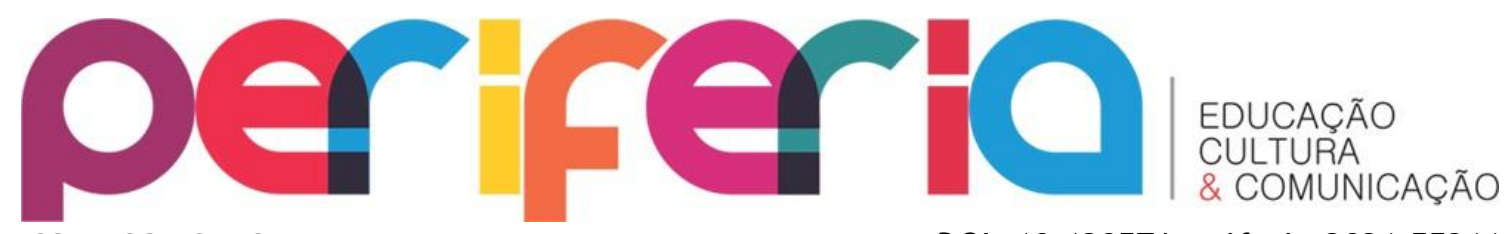

ISSN:1984-9540

DOI: $10.12957 /$ periferia.2021.55211

para o compromisso da luta por um projeto de sociedade efetivamente popular e democrático.

Nossa intenção é destacar as conquistas e avanços das políticas públicas educacionais nas comunidades camponesas a partir das Diretrizes Operacionais para a Educação Básica nas Escolas do Campo - Resolução CNE/CEB nº 1, de 3 de abril de 2002; das Diretrizes Complementares, Normas e Princípios para o desenvolvimento de políticas públicas de atendimento da Educação Básica do Campo - Resolução n 2, de 28 de abril de 2008; e do Decreto $n^{\circ} 7.352$, de 4 de novembro de 2010, que dispõe sobre a política de educação do campo e o Programa Nacional de Educação na Reforma Agrária (PRONERA). Do mesmo modo, buscamos analisar e evidenciar os principais retrocessos que se verificaram nestes últimos anos. Apesar de não serem novos na História do Brasil, tais retrocessos atingem, predominantemente, os sujeitos historicamente oprimidos e subalternizados.

Neste sentido, discutiremos os possíveis caminhos de avanço no fortalecimento das políticas públicas de educação do campo, defendendo a sua importância no conjunto da sociedade brasileira como meio de reparação histórica aos grupos historicamente marginalizados e a valorização da rica contribuição dos camponeses, quilombolas e indígenas, na formação social, política e econômica do Brasil.

A questão agrária e os movimentos sociais populares: marcos históricos da luta pela Educação do Campo

Compreender a educação do campo na atualidade nos exige o conhecimento dos marcos e processos históricos que culminaram na consolidação das políticas públicas educacionais destinadas aos povos camponeses. Trata-se da construção de lutas inerentes à formação social e político-econômica do Brasil, logo, indissociável das contradições, desigualdades, relações sociais e de poder que marcam estruturalmente este país.

É necessário traçarmos este panorama histórico para que tenhamos clareza do lugar político e social ocupado pelos camponeses e, sobretudo, das suas estratégias para superar o projeto hegemônico que se delineia no campo, trazendo cada vez 


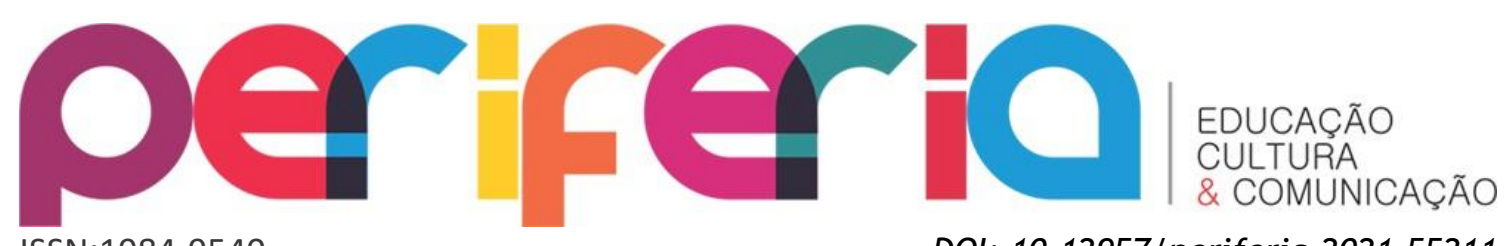

ISSN:1984-9540

DOI: $10.12957 /$ periferia. 2021.55211

mais mortes, violência física e simbólica, processos de exclusão e expropriação, exploração humana e grave risco à sustentabilidade socioambiental. Neste sentido, só compreendemos os sujeitos, individuais e coletivos, do campo, quilombolas e indígenas, e a diversidade de suas lutas, se reconhecemos que há uma profunda desigualdade histórica em relação às questões agrárias que precisam ser desveladas, discutidas e analisadas criticamente.

A realidade agrária é marcada pela concentração de terras e a permanência do grande latifúndio, em articulação com a adoção do modelo agrário-exportador, através do avanço da monocultura, do agronegócio e da mineração. Essa afirmação parte da análise histórica de como se organizou e organiza historicamente o campo brasileiro. A gênese estrutural do campo brasileiro é marcada pelo processo de desenvolvimento e acumulação capitalista, fato que permitiu aos proprietários: "a possibilidade histórica da apropriação da renda capitalista da terra, provocando uma intensificação na concentração da estrutura fundiária brasileira" (OLIVEIRA, 2005, p. 468).

Mesmo no período republicano, essa situação não se alterou. Escancarou-se os processos de expulsão dos camponeses de suas terras e o avanço das fronteiras agrícolas por meio da penetração do capital nacional e estrangeiro, permitindo a consolidação do agronegócio e outras atividades extrativistas, a partir da política de exportação e dos grandes projetos territoriais, como por exemplo, abertura de rodovias e hidrelétricas.

Este panorama da configuração agrária no Brasil, ainda que breve, é essencial para compreendermos as relações sociais e de poder no atual tempo histórico. A concentração de terras e o privilégio da classe ruralista, ratificada pelas políticas agrárias do Estado, vem desvelando uma realidade de intensos conflitos com camponeses, indígenas e quilombolas.

Diante desta difícil realidade, a resistência camponesa emerge nos múltiplos contextos sócio espaciais, organizada por meio dos movimentos sociais populares. Os sujeitos, individuais e coletivos, nas suas experiências cotidianas, defendem a terra enquanto dimensão da vida e do trabalho, necessária para soberania alimentar e produtiva através da agroecologia, do respeito à diversidade cultural, étnica e 


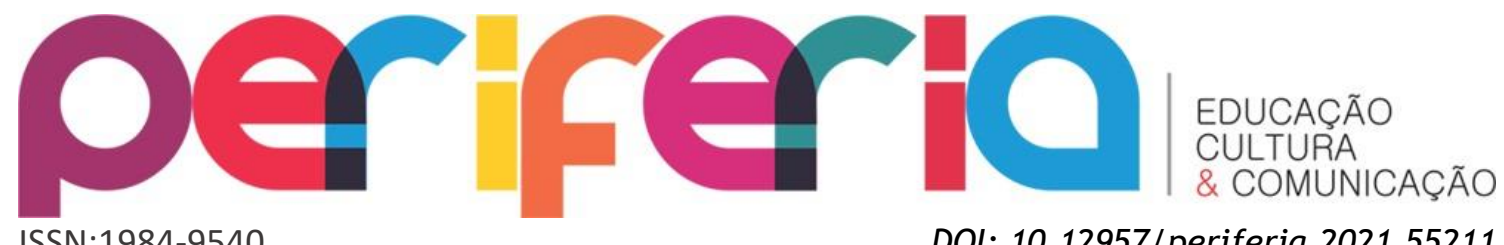

identitária. Pautam-se outros projetos de sociedade, efetivamente democráticos, com autonomia e soberania popular.

Os movimentos sociais populares, com suas várias bandeiras e expressões de luta, ganharam visibilidade na arena sócio-política. Como processo histórico, a partir da redemocratização brasileira diversas organizações populares despontaram para reivindicar demandas historicamente negadas pelo Estado. É neste momento de efervescência popular que camponeses legitimam sua existência. Mobilizam-se para que sejam reconhecidos enquanto sujeitos coletivos de direitos. Os processos educacionais, nessa conjuntura, não estão dissociados. Eles ganham notoriedade a partir da década de 1990.

É importante compreender que as políticas públicas de educação do campo nascem das disputas do movimento camponês por reforma agrária, como garantia de reprodução da existência, nos seus aspectos culturais, étnicos e identitários. Tais políticas rompem com os processos de subalternização dos camponeses historicamente construídos na sociedade brasileira. Segundo Arroyo (2014, p. 123), os movimentos sociais populares repolitizam esta subordinação: "o campo das representações sociais passa a ser um dos campos de disputa política, mas também pedagógica".

Assim, a educação do campo busca superar os processos e representações de subordinação e inferiorização. Educadores e educandos lutam para que homens e mulheres do campo, crianças, jovens e adultos se afirmem como sujeitos de direitos, exigindo do Estado políticas públicas de educação que supere os conflitos e a violência histórica presente no campo brasileiro.

$\mathrm{Na}$ década de 1990, os movimentos sociais do campo incluem a educação como uma das suas principais bandeiras de luta, enquanto direito social de todos. Eles pressionam o Estado brasileiro com o objetivo de inserir na pauta de reivindicações a reforma agrária e a elaboração de políticas públicas de transporte, escoamento da produção, lazer, saúde, entre tantos outros aspectos. Diante desta pressão, coube ao Estado reconhecer as experiências e práticas educativas originadas no interior das organizações e movimentos sociais do campo, de modo que as referidas práticas educativas fossem ampliadas e reconhecidas pela sociedade (MOLINA, 2003, 2010). 


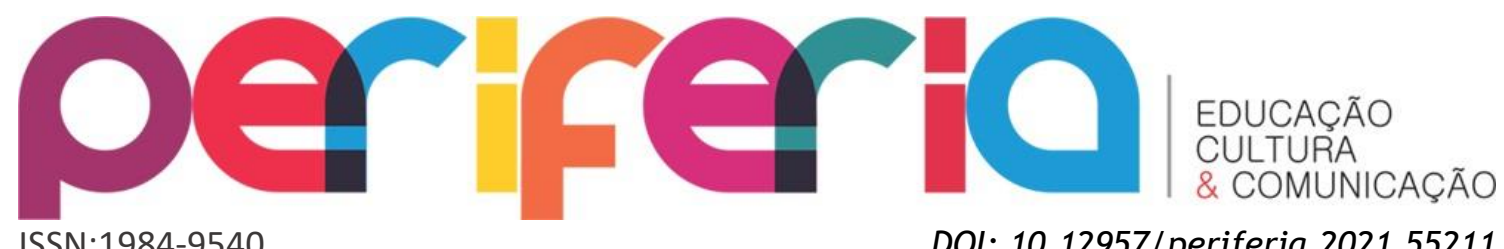

O fortalecimento e ampliação do movimento de educação do campo teve seu marco a partir da realização do I Encontro Nacional de Educadoras e Educadores da Reforma Agrária (I ENERA) em 1997, e da I Conferência Nacional "Por uma Educação Básica do Campo", ocorrido em 1998 no município de Luziânia-GO. Nesse contexto, os movimentos sociais propõem uma concepção diferenciada de organicidade com os trabalhadores e trabalhadoras do campo, englobando: reuniões periódicas, realização de seminários e acompanhamento das legislações específicas de educação básica do campo (KOLLING; NERY; MOLINA, 1999). Estando vinculada aos anseios e desejos dos movimentos sociais populares, a expressão educação do campo se dissocia, historicamente, da educação rural. Especialmente, por centralizar o camponês como sujeito histórico dotado de experiências, saberes e práticas coletivas.

O resultado deste processo culminou na Resolução CNE/CEB $n^{\circ} 1$, de 3 de abril de 2002, em que instituiu as Diretrizes Operacionais para a Educação Básica nas Escolas do Campo. Pela primeira vez houve reconhecimento dos sujeitos que vivem no e do campo. Na condução dos seus processos educativos, passam de destinatários a protagonistas. Os projetos político-pedagógicos, em diálogo com a diversidade dos sujeitos históricos, vinculam-se a realidade presente em cada contexto social.

O movimento de educação do campo no Brasil, nas duas últimas décadas, assumiu um papel efetivo na redemocratização das relações fundiárias e agrárias, como forma de superar o histórico processo de políticas assistencialistas e compensatórias. Tais políticas mantem o atraso e a precarização das escolas rurais, reforçando o abandono da educação do campo. Nesse processo de construção da concepção de educação do campo, os movimentos e as organizações representativas da classe trabalhadora do campo reivindicam:

(...) que as experiências político-pedagógicas acumuladas nesse processo de luta e mobilização, de tomada de posição nos confrontos entre concepções de agricultura, de projetos de campo, de educação e de lógica de formulação das políticas públicas sejam reconhecidas e legitimadas pelo sistema público em suas várias esferas. (HAGE; CARDOSO, 2013, p. 426). 


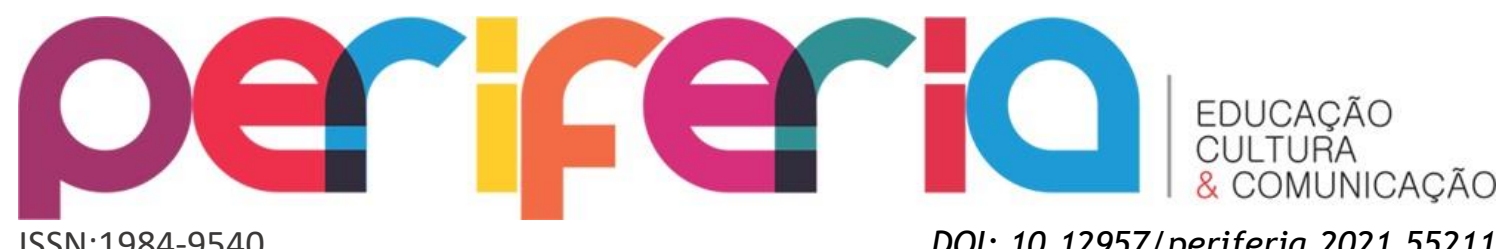

ISSN:1984-9540

DOI: $10.12957 /$ periferia.2021.55211

A construção das políticas públicas de educação do campo está na contramão das políticas neoliberais e suas medidas unilaterais e de liberdade individual. Os princípios da educação do campo enaltecem a participação coletiva e democrática, marcada pelo fortalecimento dos movimentos sociais camponeses, suas lutas e conflitos com os latifundiários. Com a aprovação de diretrizes educacionais específicas para os sujeitos do campo e a construção de processos identitários reivindicados pelos movimentos sociais populares, evidenciamos a ampliação dos dispositivos legais que asseguram o direito à educação aos estudantes do campo.

0 artigo 28 da Lei de Diretrizes e Bases da Educação Nacional (LDBEN), no que se refere à oferta da educação básica do campo, destaca que os sistemas de ensino deverão promover as adaptações necessárias observando as peculiaridades da vida rural e de cada região, especialmente: conteúdos curriculares e metodologias apropriadas às necessidades e interesses dos alunos do campo; organização escolar própria, incluindo adequação às fases do ciclo agrícola e às condições climáticas; adequação à natureza do trabalho no campo. Segundo Rossato e Praxedes (2015), esse artigo é um marco nos debates acerca das políticas públicas de educação do campo, ao determinar que os sistemas de ensino façam adaptações na gestão e organização curricular e pedagógica, valorizando as peculiaridades da realidade camponesa, a diversidade sociocultural e o direito à igualdade.

Nesse mesmo artigo, parágrafo único, incluído pela Lei nº 12.960, de 2014, a LDBEN normatiza que o fechamento das escolas do campo, indígenas e quilombolas deverá ser precedido de manifestação do órgão normativo do respectivo sistema de ensino, que considerará a justificativa apresentada a Secretaria de Educação, a análise do diagnóstico do impacto da ação e a manifestação da comunidade escolar (BRASIL, 2014).

Nota-se que as alterações mais recentes da LDBEN oferecem maior visibilidade à concepção de educação do campo, ao considerar que os sistemas de ensino do meio rural estão vinculados às escolas do campo, indígenas e quilombolas. Rompe-se com o conceito de escolas da zona rural inicialmente apresentado na legislação. O Parecer n 36/01, apresentado pela Câmera de Educação Básica, do Conselho Nacional de Educação, fixa as orientações de formulação das Diretrizes Operacionais para a Educação Básica nas Escolas do Campo. Este parecer oficializa a proposta defendida 


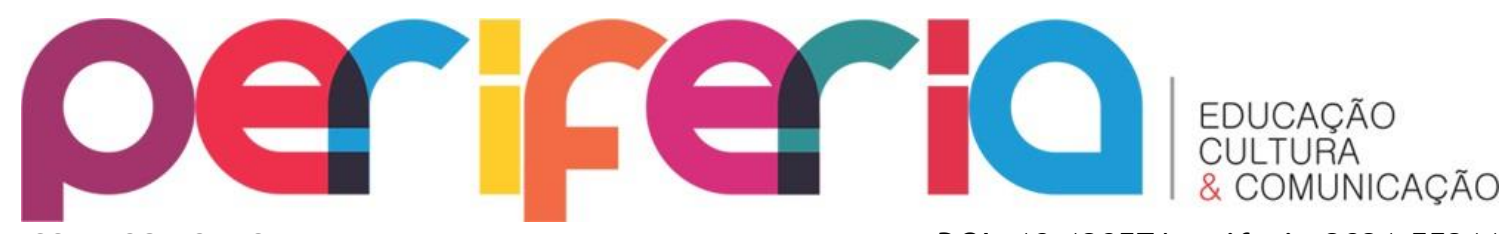

ISSN:1984-9540

DOI: $10.12957 /$ periferia.2021.55211

pelos movimentos sociais, garantindo a necessidade da educação escolar que respeite as diferenças dos sujeitos através da gestão democrática e de promoção da cidadania (ROSSATO; PRAXEDES, 2015). De acordo com o Parecer 36/2001, o campo brasileiro é "mais do que um perímetro não-urbano, é um campo de possibilidades que dinamizam a ligação dos seres humanos com a própria produção das condições da existência social e com as realizações da sociedade humana" (BRASIL, 2001).

Para Fernandes (2002), as Diretrizes Operacionais para a Educação Básica nas Escolas do Campo é um ponto de chegada de uma árdua caminhada realizada pelos movimentos sociais do campo. O campo não apenas como lugar da produção agropecuária, agroindustrial e do latifúndio, mas, também, lugar de vida permanente dos camponeses, quilombolas e indígenas. Como toda chegada é um movimento, este é um novo ponto de partida para efetivação das diretrizes, pois nenhuma conquista é garantida sem organização permanente.

Este grande esforço por parte dos movimentos sociais populares e educadores na constituição da educação do campo atenderam aos interesses das comunidades campesinas. Foi um momento oportuno e histórico para repensar os processos educativos e suas políticas públicas. Sobre a identidade dos povos camponeses, destacamos o Decreto $n^{\circ} 7.352$, de 4 de novembro de 2010, que dispõe sobre a política de educação do campo e o Programa Nacional de Educação na Reforma Agrária - PRONERA. No seu art. $1^{\circ}$, considera-se:

I - Populações do campo: os agricultores familiares, os extrativistas, os pescadores artesanais, os ribeirinhos, os assentados e acampados da reforma agrária, os trabalhadores assalariados rurais, os quilombolas, os caiçaras, os povos da floresta, os caboclos e outros que produzam suas condições materiais de existência a partir do trabalho no meio rural (BRASIL, 2010).

Trata-se de uma diversidade de sujeitos e comunidades que formam e compõe historicamente o campo brasileiro e que podem ser atendidos pelas políticas públicas de educação do campo. Ressalta-se que, a Resolução ${ }^{\circ}{ }^{\circ}$ 2, de 28 de abril de 2008, estabelece as Diretrizes complementares, normas e princípios para o desenvolvimento de políticas públicas de atendimento da Educação Básica do Campo, em todas as suas etapas e modalidades, a saber: Educação Infantil, Ensino 


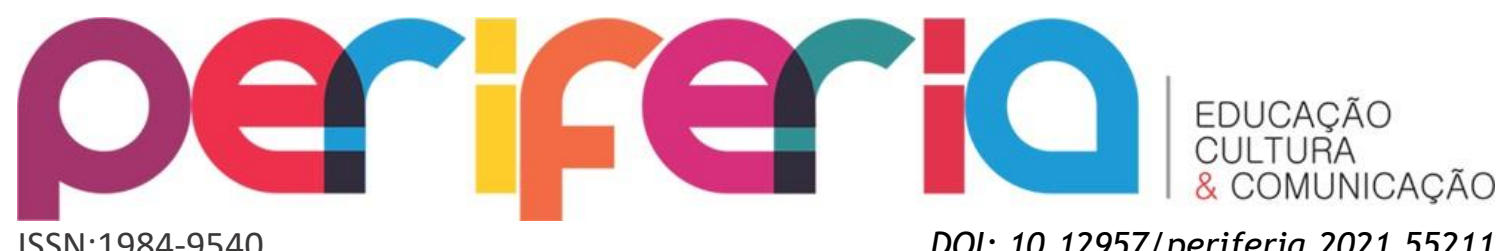

Fundamental, Ensino Médio, Educação Profissional Técnica de nível médio integrada com o Ensino médio.

O Decreto $n^{\circ} 7.352 / 2010$ também é um importante instrumento de orientação para elaboração do Projeto político-pedagógico (PPP) das escolas do campo. Ele estabelece os princípios da educação do campo, tais como: respeito à diversidade, em seus aspectos socioculturais, ambientais, políticos e econômicos; formulação de projetos referenciados na realidade local, sem excluir a diversidade de saberes historicamente acumulados; desenvolvimento de políticas de formação dos educadores e educadoras, destacando a ampliação das Licenciaturas em Educação do Campo (LEC) e a efetiva participação da comunidade e dos movimentos sociais populares do campo.

Caldart (2004), ao apresentar os elementos para construção do PPP da educação do campo, explica que o grande desafio para sua consolidação se desdobra em três tarefas combinadas: manter viva a memória da educação do campo, dinamizada e reconstruída pelos próprios sujeitos; identificar as dimensões fundamentais da luta política no momento atual; seguir na construção do PPP Projeto Político Pedagógico da educação do campo. A autora identifica alguns traços fundamentais na elaboração do PPP: 1) Formação humana vinculada a uma concepção de campo; 2) Luta por políticas públicas que garantam o acesso universal à educação; 3) Projeto de educação dos e não para os camponeses; 4) Movimentos sociais como sujeitos da educação do campo; 5) Vínculo com a matriz pedagógica do trabalho e da cultura; 6) Valorização e formação dos educadores; 7) Escola como um dos objetos principais da educação do campo. Na construção do PPP das escolas do campo, (CALDART, 2004, p. 23) destaca:

\footnotetext{
Não se trata de propor algum modelo pedagógico para as escolas do campo, mas sim de construir coletivamente algumas referências para processos pedagógicos a serem desenvolvidos pela escola e que permitam que ela seja obra e identidade dos sujeitos que ajuda a formar, com traços que a identifiquem com o projeto político e pedagógico da Educação do Campo.
}

Este breve histórico mostra que a educação do campo, enquanto modalidade da educação básica é uma conquista histórica do movimento camponês e, para tanto, 


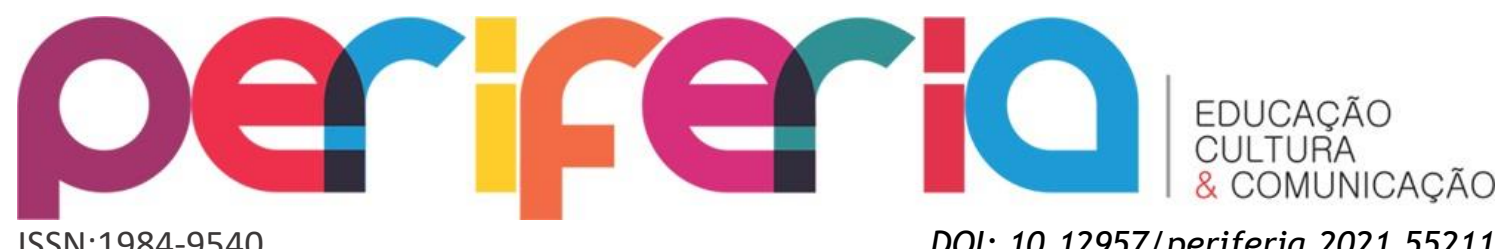

necessita ser tratada com seriedade e responsabilidade pública. Recuperar alguns dos seus pressupostos são essenciais na centralização dos sujeitos, individuais e coletivos, do campo, portadores de práticas, experiências, construção de conhecimentos e, como tal, capacidade histórica de transformação da realidade. Por outro lado, tais aspectos colaboram no entendimento acerca da dimensão e do significado atual de desmonte das políticas públicas educacionais destinadas aos camponeses. Discursos ultraconservadores apontam para ruptura democrática e possibilidade de diálogos.

\section{O desmonte das políticas públicas de educação do campo: panorama e estratégias de enfrentamento.}

Molina (2012) apresenta uma importante discussão a respeito das políticas públicas, de forma que não seria possível debatê-la sem compreendermos a dimensão do Estado, dos direitos, da democracia e dos movimentos sociais. Nessa análise, convém assinalar que a política pública envolve disputas entre sujeitos concretos e suas lutas de classes: “É exatamente o resultado das forças presentes nessa condensação das relações sociais que faz o Estado agir, ou seja, que o faz conceber e executar essa ou aquela política pública” (MOLINA, 2012, p. 591). Quando materializada, nenhuma política pública é definitiva, pois a partir de novos conflitos pode ser modificada de acordo com os interesses de classe.

Compreender essa dimensão é essencial, sobretudo, para educação do campo, pois a sua construção representou um amplo debate na sociedade civil, envolvendo disputas com interesses antagônicos (especialmente os ruralistas). A educação do campo é uma conquista dos movimentos sociais, nasceu das demandas populares pelo direito a educação de qualidade e com respeito à diversidade do campo. Pressionou o Estado no reconhecimento de sua responsabilidade pública e dívida histórica com os camponeses, quilombolas, indígenas, caiçaras, ribeirinhos, entre tantos outros sujeitos históricos.

Todo este processo é reflexo do acúmulo de experiências e lutas no campo brasileiro. É resultado de uma política agrária contraditória, excludente e desigual, privilegiando os ruralistas e o avanço do capitalismo no campo, como projeto de 


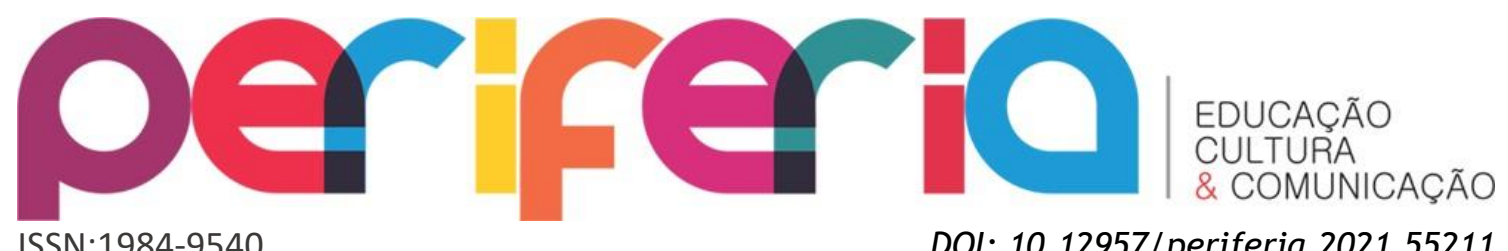

desenvolvimento adotado pelo Estado e pela classe hegemônica. A ação histórica dos movimentos sociais populares fez avançar suas reivindicações no terreno dessas contradições, permitindo a ampliação da consciência dos trabalhadores por seus direitos, como destaca (MOLINA, 2012, p. 592):

Esse movimento de ampliação da consciência dos trabalhadores que decorre de suas lutas para garantir seus direitos - entre eles, o direito à educação - tem duplo escopo de resultados: ao mesmo tempo em que vai formando os próprios trabalhadores e ampliando a sua consciência, também vai fazendo avançar a visão e a compreensão da sociedade sobre esses trabalhadores como sujeitos portadores de direitos.

Apesar das inúmeras dificuldades vivenciadas na prática cotidiana, quanto à concretização da educação do campo, os movimentos sociais populares colocam em pauta seus direitos. Porém, a conjuntura apresentada nesses últimos 5 anos, desde o processo do golpe político-parlamentar e midiático contra a ex-presidente Dilma Rousseff, se mostrou extremamente violenta para os povos do campo, em função do desmonte das políticas públicas e dos seus direitos históricos (FELICIANO, MITIDIERO, 2018).

Sinalizamos para as dificuldades de encaminhar o diálogo junto aos gestores públicos estaduais e municipais; a falta de recursos na promoção da formação inicial e continuada; processos de nucleação e fechamento das escolas do campo, submetendo estas populações a longos trajetos até a escola em núcleo urbano; descontextualização dos projetos pedagógicos e ausência da adequação do calendário escolar às especificidades locais, tais como a questão do trabalho familiar na agricultura e as condições climáticas, impedindo o deslocamento de professores até as escolas, pelas péssimas condições das estradas.

Certo que, como aponta Hage e Côrrea (2019, p. 125), "os governos de coalização do Partido dos Trabalhadores não produziram mudanças profundas na sociedade brasileira", gerando dentro dos moldes capitalistas um fraco reformismo que, apesar de alterar as condições materiais e objetivas da sociedade, com uma mínima distribuição de bens e riquezas, não foi capaz de superar a lógica neoliberal, tanto no campo, quanto na cidade (HAGE e CÔRREA, 2019). 


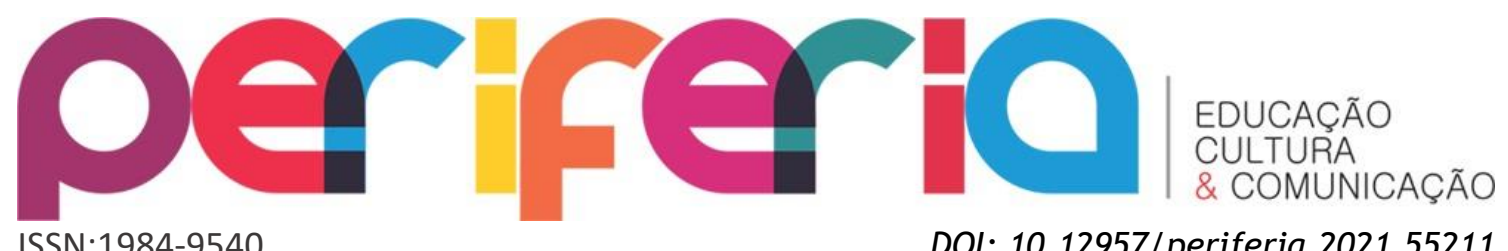

Porém, a ruptura democrática em 2015 abriu uma nova conjuntura no Brasil, trouxe novos elementos que atestam o avanço do conservadorismo e da extrema direita, fato que vem inviabilizando qualquer diálogo da classe trabalhadora no interior do Estado. Os efeitos são imediatos, pela maior vulnerabilidade e insegurança dos camponeses/as, quilombolas e indígenas frente ao ataque da classe ruralista.

A eleição de Jair Bolsonaro, no ano de 2018, representou a intensificação da ofensiva neoliberal e a reestruturação produtiva do capital, realizando as reformas trabalhista e previdenciária, com maior pauperismo para classe trabalhadora. Por outro lado, o discurso ultraconservador implica em processos de violência contra grupos historicamente oprimidos, pulverizando as políticas públicas de educação do campo, quilombola e indígena que apontavam em direção à diversidade, pluralidade cultural e ações afirmativas.

Tão logo assumiu a presidência, o atual governo editou dois Decretos que representaram uma importante derrota para promoção da política de educação do campo. O Decreto $\mathrm{n}^{\circ}$ 9.645, de 2 de janeiro de 2019, substituiu a então Secretaria de Educação Continuada, Alfabetização, Diversidade e Inclusão (SECADI). A exclusão da SECADI acompanha os retrocessos verificados já no governo de Michel Temer (2016-2018), quando por meio da Lei $n^{\circ} 13.266$, de 5 de abril de 2016, extinguiu a Secretaria de Políticas de Promoção da Igualdade Racial (SEPPIR), atualmente vinculada ao Ministério da Mulher, da Família e dos Direitos Humanos (MDH). Importante ressaltar a não dissociação entre SECADI e SEPPIR. Afinal, o encaminhamento de lutas antirracistas fortalecem as políticas de ações afirmativas e educação do campo, fundamental nas comunidades quilombolas e grande parcela de camponeses/as negros/as que compõem o campesinato brasileiro.

Outro importante desmonte ocorreu por meio do Decreto $\mathrm{n}^{\circ} 10.252$, de 20 de fevereiro de 2020, que inviabiliza o PRONERA e a condução das políticas de educação do campo nos Estados. Tal ato fragiliza as políticas de reforma agrária. Ele permite o avanço da fronteira agrícola, ampliação dos desmatamentos e concentração de terras, gerando mais conflitos e mortes no campo. No Decreto $n^{\circ} 9.660$, de $1^{\circ}$ de janeiro de 2019, o Instituto Nacional de Colonização e Reforma Agrária (INCRA) está vinculado ao Ministério da Agricultura, órgão que historicamente representa os 


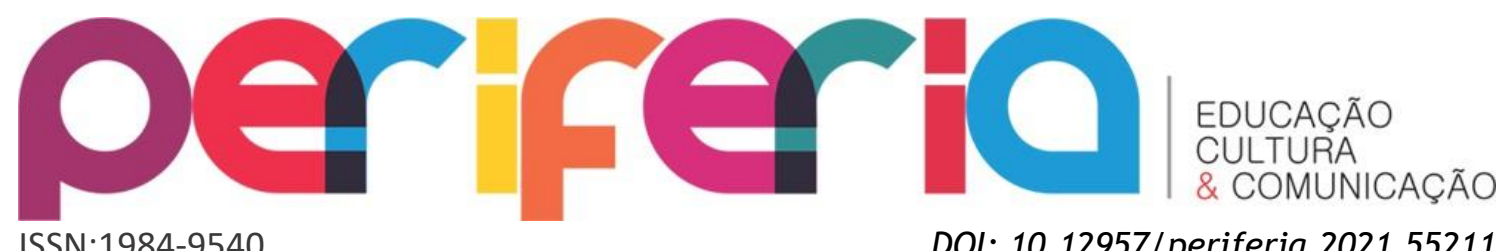

interesses das classes patronais e ruralistas. Nessa conjuntura, projetos de reforma agrária, titulação e demarcação de territórios quilombolas e indígenas tornam-se praticamente inviáveis.

Com tantos retrocessos, nega-se aos sujeitos do campo não só a educação, enquanto direito público e universal, mas também suas memórias, seus saberes, a diversidade étnico-cultural e identitária, além das formas produtivas e de organização do trabalho coletivo, enfim, seu modo de vida. Ao negar as múltiplas identidades dos sujeitos do campo, quilombolas e indígenas, impõe-se novamente uma lógica de silenciamento e imposição cultural, por meio de projetos hegemônicos.

Por outro lado, recentes declarações apontam o retorno da ideia do genocídio dos povos do campo, da intolerância à diferença, típico comportamento que pautou os três séculos de escravidão no Brasil e que embasa o discurso da extrema direita: repulsa a expressão de povos tradicionais; recusa de valores partilhados entre as comunidades tradicionais, negando a contribuição civilizatória desses povos, essenciais na formação da sociedade brasileira, além da flexibilização das leis ambientais, privilegiando a impunidade dos ruralistas, madeireiros e garimpeiros, históricos adversários dos povos camponeses.

Tais atitudes ratificam a ausência de qualquer apresso pelo diálogo, direitos humanos, ambientes democráticos e responsabilidade pública do Estado. A dimensão do retrocesso aponta para práticas políticas e discursivas que destroem, no âmbito das ações do Estado, as pautas da educação do campo. Os reflexos são sentidos, diretamente, na intensidade dos conflitos agrários.

O relatório anual da Comissão Pastoral da Terra (CPT) apontou que em 2019 foram registrados cerca de 1.833 conflitos no campo, envolvendo aproximadamente 860 mil pessoas. De acordo com a CPT, o número de conflitos em 2019 é o maior desde o ano de 2010. Envolveu também o maior número de hectares para década (53.313.244). A tipologia dos conflitos por terra varia entre ameaças de mortes, assassinatos, ordens de despejo ou expulsão, bens destruídos e ações trabalhistas. Esta realidade de violência histórica e insegurança marca estruturalmente a questão agrária brasileira, que se acirra de acordo com as conjunturas sociais, políticas e econômicas. 


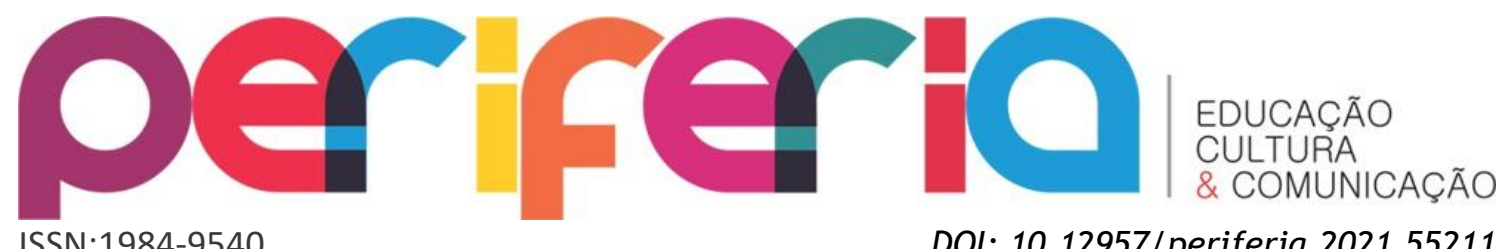

0 que se avizinha na atual conjuntura é a intensificação destes conflitos, especialmente pelo desmonte das políticas públicas, dos recursos financeiros destinados à reforma agrária (INCRA) e as questões ambientais, permitindo grilagens de terras, desmatamentos pela pecuária, atividades de garimpo, fechamento de escolas do campo, avanço do agronegócio e utilização intensa dos agrotóxicos, com claras implicações para o meio ambiente.

Porém, neste perverso contexto de dificuldades, os movimentos sociais populares resistem, rearticulando suas frentes de luta ao conservadorismo. É interessante perceber que, apesar do número de ocupações terem diminuído em 2019, se comparado com o ano de 2018 (43 contra 143, respectivamente), os dados da CPT (2019) apontam um aumento no número de manifestações, de 538 em 2018, para 1301 em 2019. Ou seja, os movimentos sociais populares conseguem traçar, diante da radicalidade ofensiva do atual governo, novas estratégias de luta e reinvindicação.

Segundo Ribeiro (2013, p. 277): "os movimentos sociais expressam a luta de classes e não há movimento social que não seja também político". Numa sociedade de classes, profundamente desigual, os movimentos sociais populares encaminham suas lutas e reivindicações a partir das experiências concretas. Eles educam sujeitos, homens e mulheres, para consciência crítica da realidade, capacidade de intervenção e transformação emancipadora.

A mobilização dos sujeitos, individuais e coletivos, no interior das comunidades, os encontros e as trocas de saberes promovidas por camponeses/as, universidades públicas, fóruns, secretarias municipais e estaduais de educação, contribuem com os debates acerca das políticas públicas de educação nas escolas do campo. Trabalha-se com a formação política, filosófica e emancipadora dos camponeses, incentivando os núcleos de agroecologia e a produção de alimentos saudáveis, nos marcos da autonomia e soberania alimentar.

As ocupações de terra e a luta pela reforma agrária popular, embora com dificuldades, pela impunidade da violência imposta pelos ruralistas, caminham. Experiências, individuais e coletivas, apontam para o horizonte de rearticulação das lutas populares. A continuidade do trabalho coletivo de homens e mulheres, crianças, jovens e adultos, pode colaborar no enfrentamento dos retrocessos atuais. 


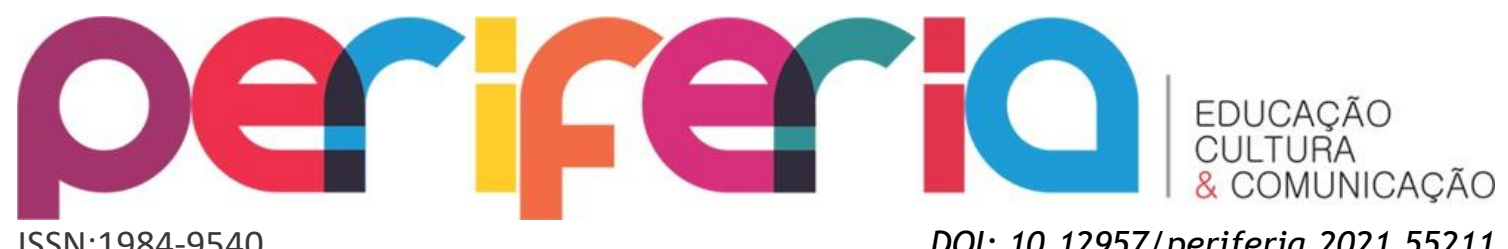

Tais ações reforçam que, apesar do viés autocrático e autoritário presente no Estado brasileiro, o movimento da educação do campo continua intenso entre camponeses/as. Com espaços públicos de debates, mobilizam os sujeitos e esboçam novas estratégias emancipatórias frente à conjuntura de desmonte e ausência de recursos públicos. É responsabilidade pública do Estado a oferta da educação do campo. Nesse sentido, ela continua sendo disputada na sociedade civil, tencionando concepções de formação política, educativa e humana, fazendo avançar a diversidade de lutas por escolas do campo e reforma agrária popular, numa intensa articulação com um novo projeto de sociedade.

Apesar do desprezo do atual governo quanto às demandas populares relacionadas aos trabalhadores do campo e da cidade, os movimentos sociais populares rearticulam suas frentes de mobilização e luta, na interface com as experiências históricas de suas bases. Essa organicidade gera novos aprendizados para o conjunto da classe trabalhadora, especialmente em relação à função do Estado e a opressão estabelecida pela classe dominante. Segundo (ARROYO, 2014, p. 295):

Um dos aprendizados mais radicais dos coletivos em lutas por direitos é sobre a função da natureza do Estado. Um aprendizado que não vem de fora, de cartilhas e conteúdos críticos nem de processos educativos conscientizadores de fora, mas vem das tensas vivências e das experiências concretas, de lutas coletivas por direitos no interior do Estado, de suas instituições e políticas (...) descobrem a histórica função do Estado e os limites de suas políticas distributivas, compensatórias.

Compreender tais limites mostra que as políticas públicas não são permanentes. Elas devem ser constantemente disputadas, com a intenção de garantir as condições objetivas de materialização e implementação no Estado. Os novos aprendizados quanto à natureza e função desse Estado, representante máximo dos interesses da burguesia, e nela, os ruralistas e grandes proprietários de terra, contribui na rearticulação das lutas para disputá-lo. Nessa conjuntura, avançar na participação, efetivamente popular, da classe trabalhadora, estabelecendo alianças com os movimentos sociais, partidos políticos e sindicatos, é urgente e estratégico na consolidação dos princípios democráticos. 


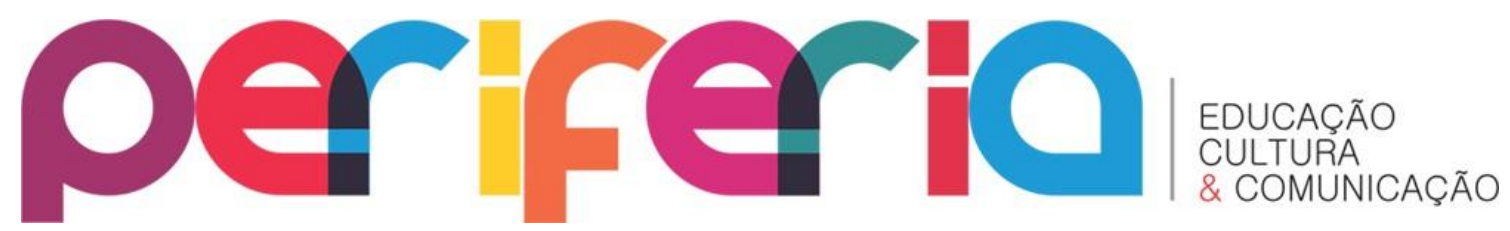

ISSN:1984-9540

DOI: 10.12957/periferia.2021.55211

\section{Considerações Finais}

Retomamos as contribuições de Caldart (2004) quanto à afirmação de que uma das tarefas da educação do campo é manter viva os seus princípios educativos e os fundamentos político-filosóficos, articulados com as ações concreta da realidade. Em meio a tantos retrocessos, a memória é um dos campos em disputa. E não se trata apenas do aspecto subjetivo, de imposição do projeto hegemônico de educação que busca silenciar a diversidade étnico-cultural do campesinato brasileiro, mas também nos aspectos objetivos, de desmonte das políticas públicas. Tal desmonte favorece a violência no campo e destrói o modo de vida camponês, quilombola e indígena, em função do avanço do agronegócio, da mineração e dos grandes projetos territoriais que favorecem a acumulação do capital.

Tal conjuntura lança novas etapas de articulação e enfrentamento aos movimentos sociais populares. Disputar a memória e a consciência dos trabalhadores/as do campo, além da formação política, é essencial. Ela desperta, a partir das experiências concretas de homens e mulheres, a crítica da realidade e suas contradições, possibilitando a implementação de um projeto popular de sociedade.

Ao mesmo tempo, é fundamental a sensibilidade e leitura crítica em relação ao que vem sendo construído pelos movimentos sociais populares, em suas diversas formas de organização coletiva. Seja no interior das comunidades, nos eventos das universidades públicas ou nos fóruns de educação do campo, tais movimentos potencializam suas práticas e experiências educativas, mobilizando a sociedade civil acerca da importância da educação do campo, como meio de superação da opressão e subalternização de camponeses/as. Elaboram-se novos projetos no campo brasileiro, respeitando a diversidade cultural, saberes, fazeres e práticas produtivas.

Por fim, como horizonte de esperança, as recentes manifestações de cunho antifascista e antirracista, diante da realidade de violência contra os trabalhadores e de pauperismo absoluto, são indícios de retomada do debate popular quanto aos rumos da atual conjuntura. Tomar as ruas é fazer ecoar a luta por direitos e contra a opressão, mobilizando os trabalhadores/as para o avanço da democracia, justiça social no campo, autonomia e soberania popular. Do mesmo modo, indica a 


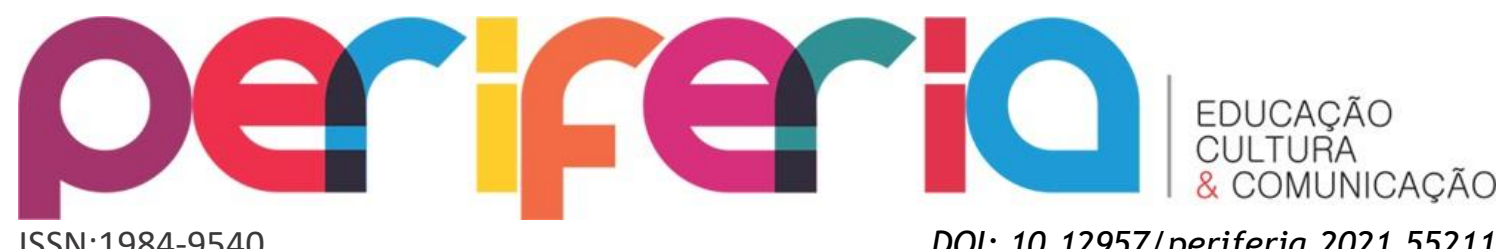

importância de uma frente ampla de aproximação entre os trabalhadores/as do campo e da cidade, dependentes uns dos outros, na elevação do projeto de educação popular, camponesa e emancipadora.

Portanto, este é um dos desafios que se colocam no atual tempo histórico, defender a educação enquanto direito social, referenciada e contextualizada na diversidade e pluralidade, ampliando os espaços de diálogos e construção coletiva, na luta por justiça, dignidade e respeito.

\section{Referências}

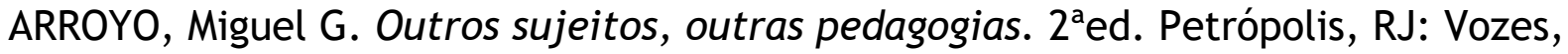
2014.

BRASIL. Constituição (1988). Constituição da República Federativa do Brasil. Brasília, DF, Senado, 1998.

BRASIL. Ministério da Educação. Decreto $n^{\circ}$ 7.352, de 4 de novembro de 2010. Dispõe sobre a política de educação do campo e o Programa Nacional de Educação na Reforma Agrária - PRONERA. Diário Oficial da União, Brasília, 2010.

BRASIL. Lei $\mathrm{n}^{\circ}$ 9.394, de 20 de dezembro de 1996. Estabelece as Diretrizes e Bases da Educação Nacional. Diário Oficial da União, Brasília, DF, 1996.

BRASIL. Ministério da Educação. Parecer CNE/CEB 36, de 4 de dezembro de 2001. Diretrizes Operacionais para a Educação Básica nas Escolas do Campo. Brasília: MEC, 2001.

BRASIL. Ministério da Educação. Conselho Nacional de Educação. Resolução CNE/CEB n ${ }^{\circ} 1$, de 3 de abril de 2002. Institui Diretrizes Operacionais para a Educação Básica nas Escolas do Campo. Brasília, 2002.

BRASIL. Ministério da Educação. Conselho Nacional de Educação. Resolução $\mathrm{CNE} / \mathrm{CEB} \mathrm{n}^{\circ} 2$, de 28 de abril de 2008. Estabelece diretrizes complementares, normais e princípios para o desenvolvimento de políticas públicas de atendimento da educação básica do campo. Brasília, 2008.

CALDART, Roseli Salete. Elementos para construção do projeto político e pedagógico da educação do campo. In: Por uma educação do campo: contribuições para a construção de um projeto de educação do campo. V. 5. Brasília: 2004, p. 10 $-31$.

COMISSÃO PASTORAL DA TERRA. Conflitos no Campo: Brasil 2019. Goiânia: CPT Nacional, 2020. 


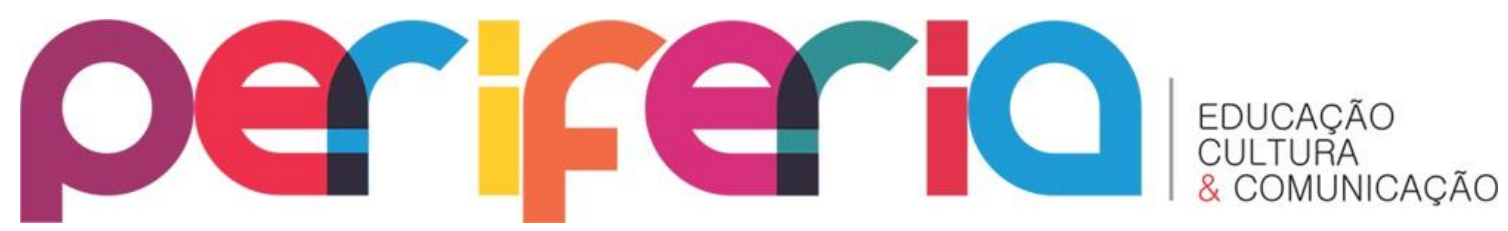

ISSN:1984-9540

DOI: 10.12957/periferia.2021.55211

FELICIANO, Carlos Alberto; MITIDIERO JUNIOR, Marcos. A violência no campo brasileiro em tempos de golpe e a acumulação primitiva de capital. Okara: Geografia em debate, v.12, n² 2, p. 220-246, 2018.

FERNANDES, Bernardo Mançano. Diretrizes de uma caminhada. In: KOLLING, Edgar Jorge, CERIOLI, Paulo Ricardo, CALDART, Roseli Salete (Orgs.) Educação do Campo: identidade e políticas públicas. Brasília: Articulação Nacional por uma Educação Básica do Campo, 2002, p. 89-101.

GUIMARÃES, Fábio; BICALHO, Ramofly. Desafios da Educação do Campo: fechamento das escolas do campo no Brasil. In: SANTOS, Ramofly Bicalho (org.). Possiveis interfaces entre educação do campo, educação popular e questões agrárias. 1 ed. Curitiba: Appris, 2017. P. 129 - 157.

HAGE, Salomão Antonio Mufarrej; CARDOSO, Maria Bárbara da Costa Cardoso. Educação do campo na Amazônia: interfaces com a educação quilombola. Revista Retratos da Escola, Brasília, v. 7, n. 13, p. 425-438, jul/dez. 2013.

HAGE, Salomão Antônio Mufarrej. CORRÊA, Sérgio Roberto Moraes. Educação Popular e Educação do Campo na Amazônia: análise a partir dos movimentos sociais. Revista Trabalho, Política e Sociedade, vol. IV, nº.7, p.123-142, jul./dez. 2019.

KOLLING, Edgar Jorge; NERY, Irmão Israel e MOLINA, Mônica Castagna. Por uma educação básica do campo (Memória). Brasília/DF: Fundação Universidade de Brasília, 1999.

MOLINA, Mônica Castagna. A contribuição do PRONERA na construção de políticas públicas de educação do campo e desenvolvimento sustentável. 2003. Tese (Doutorado em Desenvolvimento Sustentável) Centro de Desenvolvimento Sustentável da Universidade de Brasília, 2003.

MOLINA, Mônica Castagna. (org.) Educação do Campo e Pesquisa II: questões para reflexão. Brasília: MDA/MEC, 2010.

MOLINA, Mônica Castagna. Políticas Públicas. In: CALDART, Roseli Salete. et al. (orgs.). Dicionário da Educação do Campo. $2^{\mathrm{a}}$. ed. Rio de Janeiro, São Paulo: Escola Politécnica de Saúde Joaquim Venâncio, Expressão Popular, 2012.

OLIVEIRA, Ariovaldo Umbelino de. Agricultura brasileira: transformações recentes. In: ROSS, Jurandyr L. Sanches (org.). Geografia do Brasil. $5^{a}$ ed. São Paulo: EDUSP, 2005. p. 465-547.

ROSSATO, Geovanio; PRAXEDES, Walter. Fundamentos da educação do campo: história, legislação, identidades camponesas e pedagogia. São Paulo: Editora Loyola, 2015. 


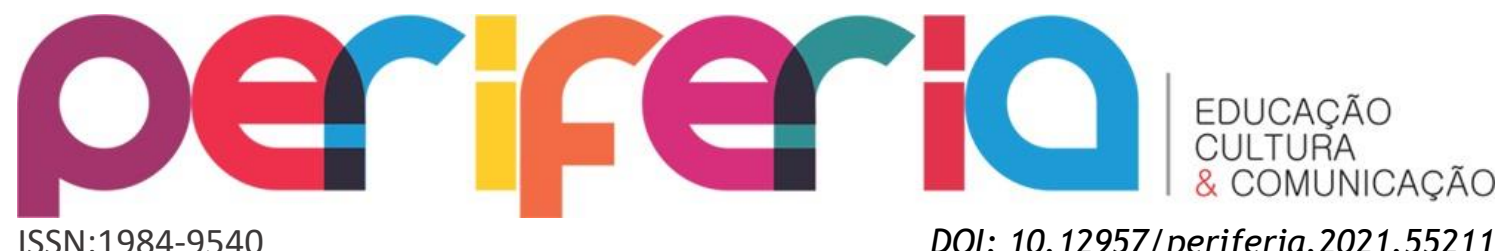

RIBEIRO, Marlene. Movimento camponês, trabalho e educação: liberdade, autonomia e emancipação. $2^{a}$ ed. São Paulo: Expressão Popular, 2013. 